\title{
THE NSW PUBLIC HEALTH OFFICER TRAINING PROGRAM PLACEMENTS, 1997
}

Fou Public Health Officers completed their competencies and have left the program.

They are:

Suzanne Blogg

Hugh Burke

Gerard Fitzsimmons

Jeannine Liddle

All four have been successful in securing positions and we

wish them well in their careers.
Four new trainees joined the program in February 1997.

They are:

Mark Bartlett

Larissa McIntyre

Julianne Quaine

Sarah Thackway

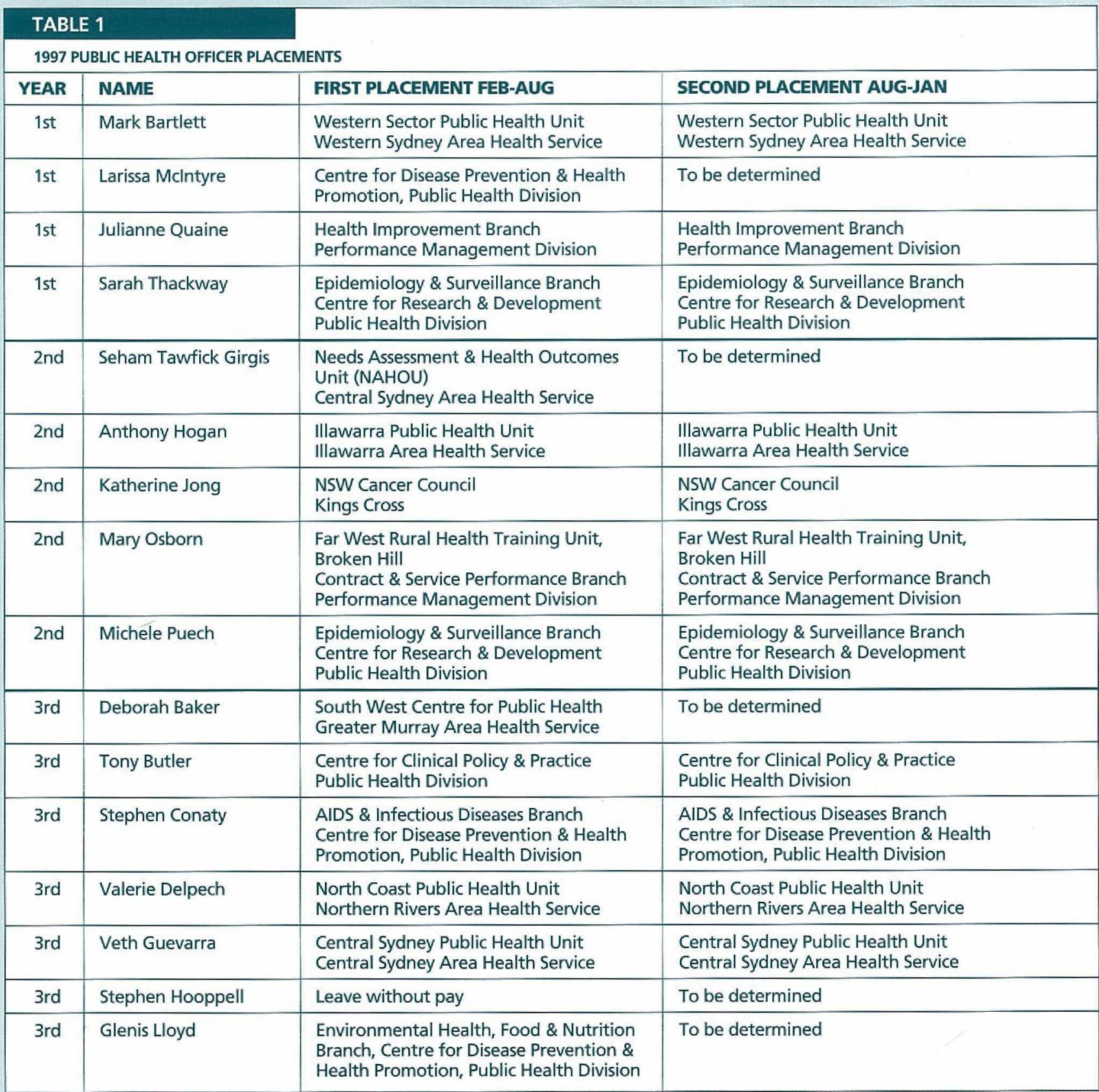

